\title{
Social Resilience to Climate Change during the Late Antique Little Ice Age: A Replication Study
}

\author{
PETER N. PEREGRINE \\ Lawrence University, Appleton, Wisconsin, and Human Relations Area Files Advanced Research Center at Yale University, \\ New Haven, Connecticut
}

(Manuscript received 25 February 2020, in final form 22 May 2020)

\begin{abstract}
In a recent Weather, Climate, and Society article, two hypotheses about social resilience to disaster were tested. One was that societies allowing greater political participation and access to decision-making were more resilient to catastrophic climate-related disasters; the second was that societies with stronger social norms were more resilient. Support was found for the first hypothesis but little support for the second. The lack of support for the second hypothesis seemed odd, as it had been supported by other researchers, but a clear rationale for the lack of support was not offered. Here the previous study is replicated with a sample of 20 societies that experienced the Late Antique Little Ice Age. As with the original paper, the replication finds support for the first hypothesis and little support for the second. It is suggested that the reason for these differing results is due to the differing forms of climate-related disasters examined in previous studies. Specifically, it is suggested that political participation provides resilience to catastrophic climate-related disasters by fostering bridging forms of social capital, whereas adherence to strong social norms provides resilience to smaller, more episodic disasters by fostering bonding forms of social capital. The paper concludes with policy suggestions that are based on these findings.
\end{abstract}

\section{SIGNIFICANCE STATEMENT}

This paper replicates a previous study published in Weather, Climate, and Society. Both the previous study and this replication find that societies providing greater access to political participation and decision-making are more resilient to catastrophic climate-related disasters than societies having strong social norms, the latter being an argument made by other researchers. The findings suggest that better resilience is fostered when stakeholders are directly involved in decision-making. Thus, in addition to replicating the previous study, this study supports current research on disaster response and management arguing that social capital and community engagement should be fostered to build resilience to climate-related disasters.

\section{Introduction}

In a recent Weather, Climate, and Society paper I tested two hypotheses concerning social resilience to catastrophic climate-related disasters (Peregrine 2018a). The first was that more resilient societies provided citizens with greater opportunities for political participation. I found solid support for this hypothesis. Second, I tested the hypothesis that more resilient societies have tighter social norms that are adhered to strongly. I found little support for this hypothesis, but I was unsure why support was so weak, as the hypothesis had been supported

Corresponding author: Peter N. Peregrine, peter.n.peregrine@ lawrence.edu by other researchers (Harrington and Gelfand 2014). Here I undertake a replication of the previous study using a new sample of societies all of which experienced the same catastrophic climate-related disaster-the Late Antique Little Ice Age (LALIA). I also provide a possible explanation for why the second hypothesis is not supported in either of these studies. Last, I offer some suggestions as to how we might use the findings from these two studies to develop social mechanisms or interventions to build social resilience to climate change.

The sample of societies that I use in this replication all experienced the dramatic impact of three massive volcanic eruptions that took place in 536, 540, and $547 \mathrm{CE}$, respectively (Büntgen et al. 2016). Contemporary witnesses to the $536 \mathrm{CE}$ event tell us that the sky darkened, 


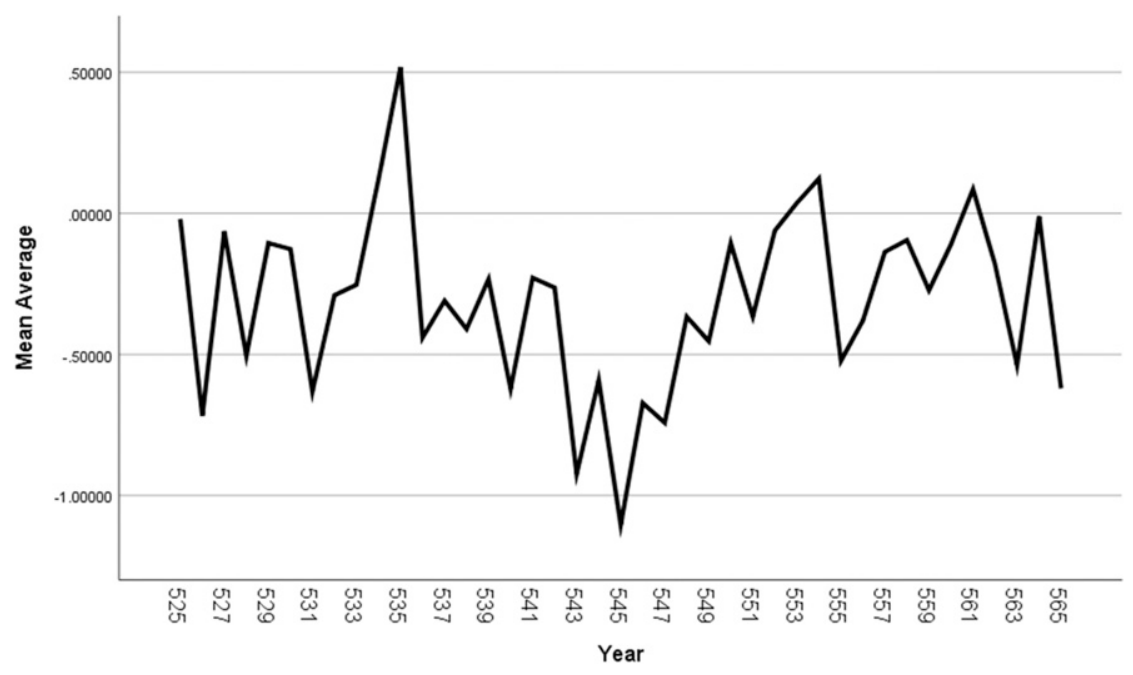

FIG. 1. Mean annual temperature trend for the 20 sample locations.

the weather cooled, and for the next 18 months the sun "shone for about four hours, and still this light was only a feeble shadow" [John of Ephesos, quoted in Arjava (2005)]. The second and third eruptions intensified the impact of the first and forced a period of dramatic climate change that saw mean annual temperatures across the Northern Hemisphere drop by more than $1^{\circ} \mathrm{C}$ in less than a decade (Neukom et al. 2019; Peregrine 2020b) (Fig. 1). The climate did not recover from this event for nearly 20 years, and by that time many societies the Northern Hemisphere had experienced profound (and in some cases irreversible) disruption (see, e.g., Gräslund and Price 2012; Gunn 2000; Löwenborg 2012; Toohey et al. 2016). The exact locations of these eruptions are debated (Nooren et al. 2017), but it is clear that they produced the largest and longest atmospheric loading event in recorded history (Dull et al. 2019). Although terrible for the people who experienced it, this extraordinary climate-related catastrophe took place during a period for which both good archaeological data and good historical data are available, and thus it provides the context for a naturalistic experiment through which to test hypotheses about social vulnerability and resilience (Peregrine 2020b; Riede 2014; van Bavel and Curtis 2016).

As explained in the paper whose results I replicate here (Peregrine 2018a), the concept of social resilience as I use it refers to "adaptive resilience," which is the capacity of a social system "to successfully avoid crossing into an undesirable system regime, or to succeed in crossing back into a desirable one" following a disaster (Walker et al. 2004). This is opposed to "transformative resilience," which refers to the capacity of a social system "to create a fundamentally new system" following a disaster (Walker et al. 2004). Using these definitions, one might expect a society with adaptive resilience to return to a state of equilibrium or controlled positive feedback following a disaster that is similar to what existed previously [but not identical to it, as a resilient system will change to reduce future risk-see Wisner and Kelman (2015)]. A society with transformative resilience, on the other hand, might be seen as fundamentally changing its predisaster structures so as to achieve a new equilibrium or controlled state of positive feedback.

\section{Resilience, political strategies, and societal tightness}

This section of the paper provides a review of the study replicated here and a description of the sample and methods employed in the replication. Three key concepts are introduced: adaptive resilience, corporate political strategies, and societal tightness (see Table 1). The two hypotheses tested in the replication are also introduced.

The literature on social resilience to disaster is vast, and any review of that literature in an article of this length must be superficial at best (see, e.g., Tiernan et al. 2019). A major theme in the literature on resilience to climate-related disasters that I focus on is the notion that more "flexible" social structures provide greater resilience. The arguments for this are complicated, but they fundamentally center on the idea that flexible structures allow for greater coordination and innovation in preparation for and in response to a disaster (e.g., Aldrich 2012; Holling et al. 2002; Kahn 2005; Paton 2006; Riede 2017). This is particularly true for adaptive resilience, 
TABLE 1. Summary of key concepts employed in the paper.

\begin{tabular}{|c|c|}
\hline Adaptive resilience & $\begin{array}{l}\text { The capacity of a society's basic social structures and relationships to absorb the shock of a catastrophic } \\
\text { disaster and to alter in ways that will prevent future shocks from destroying them }\end{array}$ \\
\hline & Refers to relationships and organizations that build strong interpersonal bonds within communities \\
\hline Bri & $\begin{array}{l}\text { Refers to relationships and organizations that build bonds between communities, agencies, and } \\
\text { governments, as well as bonds across groups within communities }\end{array}$ \\
\hline Corpo & $\begin{array}{l}\text { A political strategy in which leaders encourage broad political participation, promote a collective } \\
\text { ideology, and legitimate their authority through appeal to leadership as a means to achieve } \\
\text { collective goals }\end{array}$ \\
\hline & Governance systems that operate as a multilevel hierarchy of semi-independent decision-making groups \\
\hline Socie & $\begin{array}{l}\text { A tight society has rigid social norms to which individuals are expected to rigorously adhere, to the degree } \\
\text { that violations might be formally punished }\end{array}$ \\
\hline
\end{tabular}

for flexibility is one of the features that allows societies to adapt rather than transform. I refer to this idea as "flexibility theory" for ease of discussion, although it is referred to by many terms in the literature.

A different argument has been made by M. Gelfand and colleagues (Gelfand et al. 2011; Harrington and Gelfand 2014; Jackson et al. 2020). They suggest that societies facing frequent natural disasters and hazards (climate-related disasters as well as conflict and epidemic disease) tend to be "tighter" than other societies; that is, they have strong social norms that are stringently adhered to. They posit that these strong social norms provide societies with opportunities for greater coordination to deal effectively with disasters (Gelfand et al. 2011, p. 1101; van Bavel and Curtis 2016). I refer to this perspective as "tightness theory" in this paper for ease of discussion.

While both flexibility theory and tightness theory focus on social adaptations to dynamic conditions, they put forward contrasting ideas about the social roots of adaptive resilience to climate-related disasters. Flexibility theory envisions broad political participation, open lines of communication, and fluid mechanisms of coordination as the key to resilience. Tightness theory envisions strong norms of behavior fostering well-coordinated responses as key.

In my previous study I developed index measures for both societal flexibility and societal tightness, and the logic for those indices is described in some detail there. Here I only outline these indices and hope readers will refer to my earlier paper (Peregrine 2018a) and online data (archived at http://hrafarc.org) for more information. Flexibility is measured through the corporateexclusionary index (CEI). This index is based on five variables measuring the degree to which political leaders stress communal ideals, broad participation in decisionmaking, and freedom in interactions outside the polity (Table 2). Tightness is measured through the loosenesstightness index (LTI). This index is based on six variables measuring the extent to which there is strong emphasis on and expectations of adherence to social norms (Table 3).

Using these indices as the independent variables I put forward two hypotheses about social resilience to catastrophic climate-related disasters:

Hypothesis 1-Societies with more corporate political strategies are more resilient to catastrophic climaterelated disasters.

Hypothesis 2-Societies with tighter adherence to social norms are more resilient to catastrophic climate-related disasters.

These two hypotheses were tested with a sample of societies bracketing 22 distinct catastrophic climate-related disasters in nine world regions (Fig. 2). Individual cases consisted of those archaeologically known societies inhabiting a specific region impacted by the disaster; with one case representing the time period within 100 years before the disaster and another the time period within 100 years after the disaster. The sample cases and sampling criteria are described in my previous paper along with the catastrophic climate-related disasters that impacted them. I found strong associations between more corporately oriented polities and stability following a catastrophic disaster, supporting hypothesis 1 . However, I found no relationship between societal tightness and stability, and I therefore rejected hypothesis 2 .

Rejection of hypothesis 2 was surprising, as tightness theory has been empirically supported elsewhere (Gelfand et al. 2011; Harrington and Gelfand 2014). I provided several ideas to explain the lack of support for hypothesis 2 , one of which seemed promising to me: "different scales of impact (i.e., societal wide versus community) may also require different strategies of resilience" (Peregrine 2018a, p. 156). Thus I suggest that societal tightness may be associated with resilience to localized disasters in which neighbors are often first responders and are a vital source of support following the disaster whereas corporate orientation may be more associated with resilience to catastrophic disasters. 
TABLE 2. CEI codes, reproduced from Peregrine (2018a).

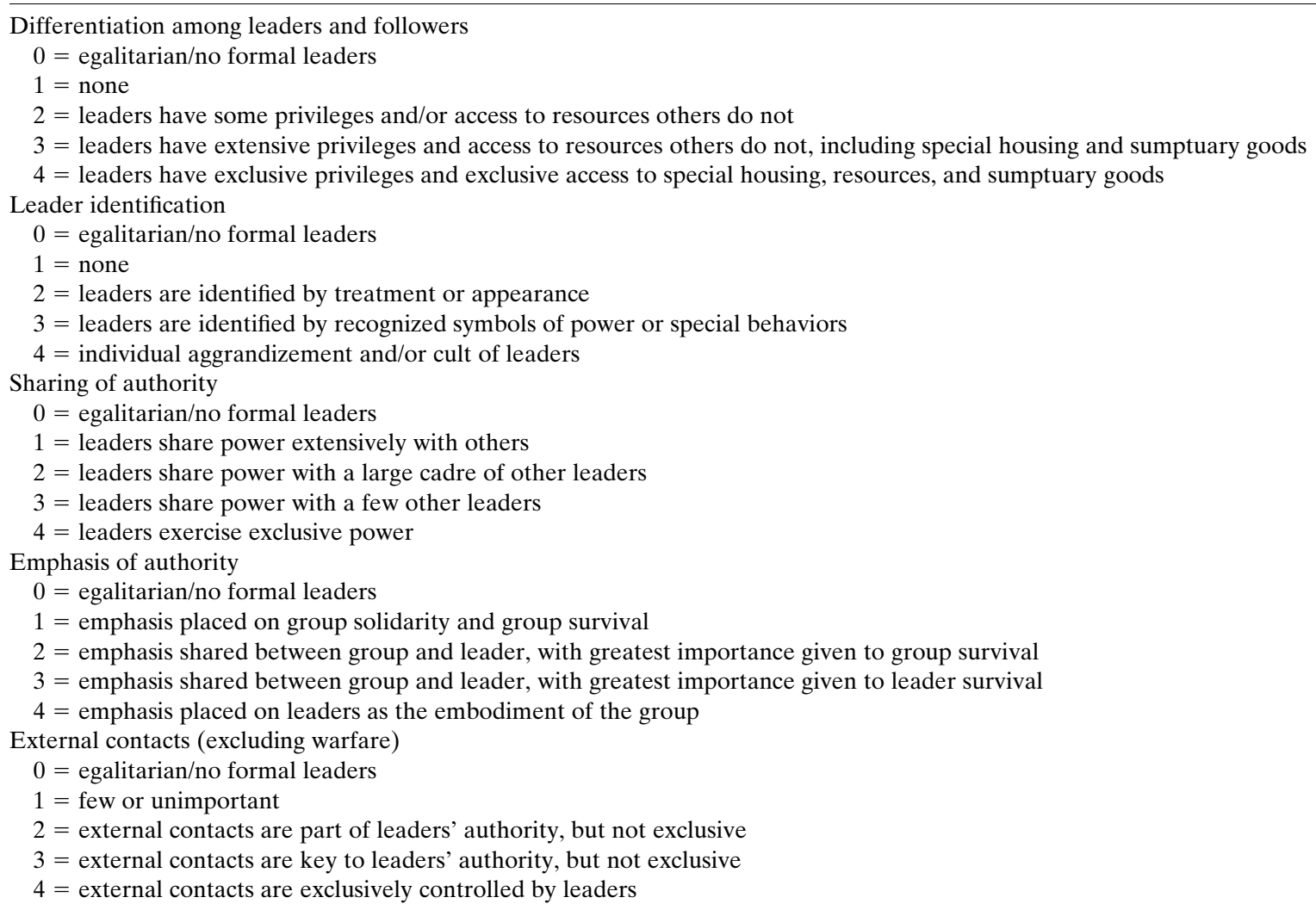

I develop this idea in the remainder of this paper, and come to the conclusion that flexibility theory and tightness theory are each associated with a specific form of social capital—bridging and bonding, respectively—and that these forms of social capital are differentially adaptive to different scales of climate-related disasters.

\section{Methods}

In this section I provide a description of the sample, coding methods, and variables used to replicate the study described above. Much of the material introduced in this section is available online, including the complete codebook, raw data, and additional statistical analyses (see http://hrafarc.org).

\section{a. Sample}

The sample of societies used in this study was selected based on three criteria: that they experienced the LALIA, that they had adequate historical and archaeological information to allow coding, and that they were geographically and linguistically distant enough to avoid autocorrelation ("Galton's Problem"; see Dow 2007). First, three cases coded for the project replicated here overlapped the LALIA and were selected for analysis. The dependent variables used in this study were already coded for these three cases, had already been demonstrated to be valid and reliable, and provided a clear protocol for extending coding to the new cases.

Second, 12 cases were selected from the Seshat Databank World Sample 30 (http://seshatdatabank.info/methods/ world-sample-30/). The Seshat Databank assembles historical and archaeological textual, visual, and numerical information to provide a source of data to test hypotheses about long-term cultural stability and change (Turchin et al. 2018). In developing the Seshat Databank World Sample 30, the world was divided into 10 major regions, within each of which three differing natural geographic areas (NGAs) were selected. The selection criteria for NGAs included a desire to represent a wide range of sociopolitical forms, so that information would be coded for as wide a range of societies as possible. The Seshat Databank World Sample 30 includes 12 locations in the Northern Hemisphere with societies that had experienced the LALIA, and these 12 cases were selected.

Third, five cases were added to ensure that there would be some coverage of all major regions of the 
TABLE 3. LTI codes, reproduced from Peregrine (2018a). "Unstandardized" implies that the range of variation extends far beyond a basic set of forms or types; "moderately unstandardized" implies that, while they follow a basic set of forms or types, most items are also routinely altered or personalized to create a relatively large range of variation within those basic forms or types; "moderately standardized" implies that basic forms or types are generally followed, albeit with variation due to individual manufacture or preference; "standardized" implies strong adherence to basic forms or types with relatively little variation.

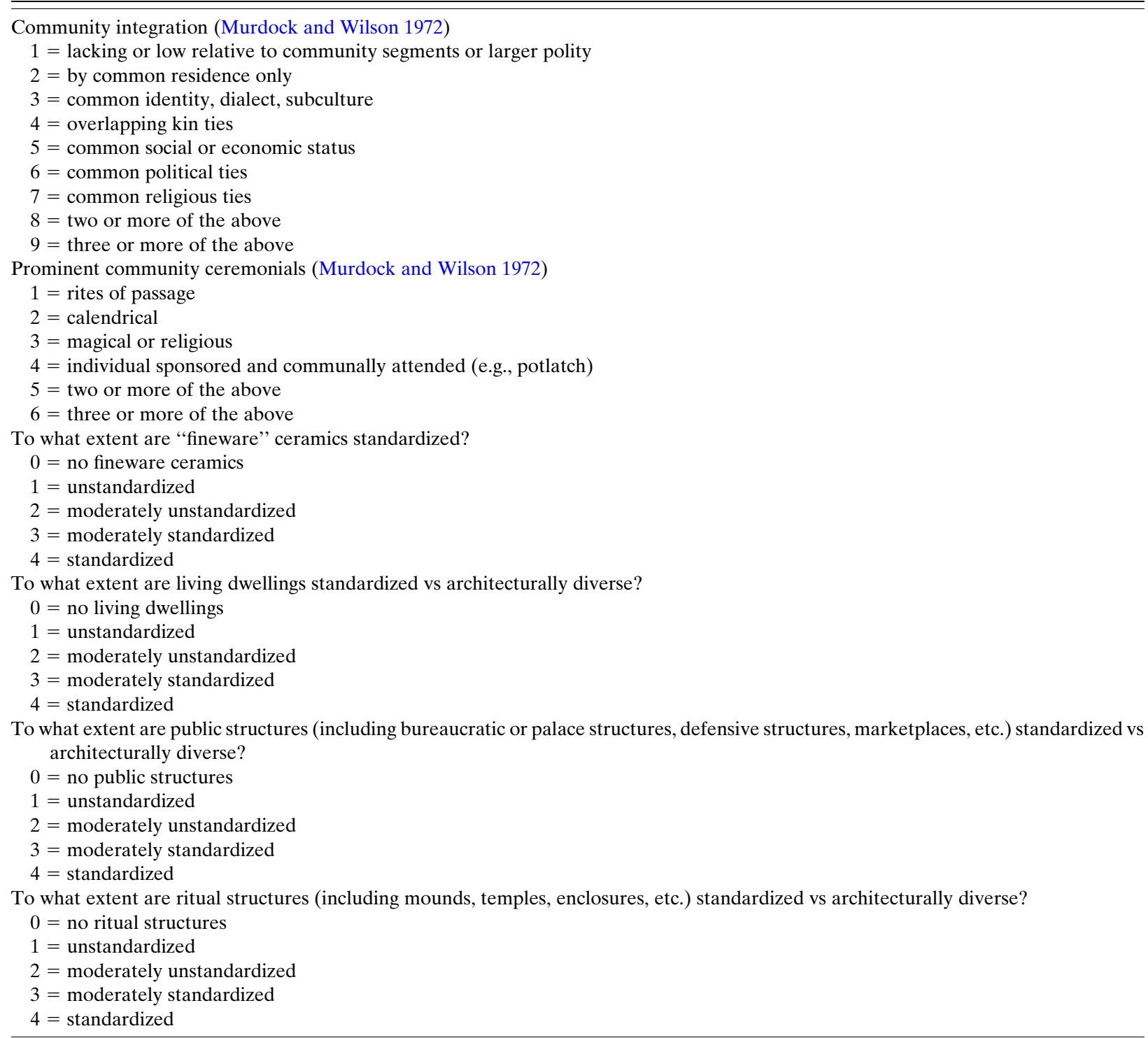

Northern Hemisphere. These five additional cases were selected (as were all of the others) from areas with well-studied archaeological and historical records and that were geographically and linguistically distant enough from other societies in the sample to minimize autocorrelation. The locations of the cases are shown in Fig. 3.

\section{b. Variables}

The independent variables used in the previous analysis and discussed briefly above were employed in this replication. The CEI is calculated as the average standardized scores on the five variables listed in Table 2. More corporate societies score lower on the scale, having agents that encourage subjects to participate in political activities, that share authority broadly, and that allow subjects unencumbered interaction with outsiders. The opposite is true in more exclusionary societies. The CEI was coded identically to the previous study and remained a very robust index with an alpha of 0.910. All the variables in the CEI load onto a single factor explaining $74.4 \%$ of the variance. 


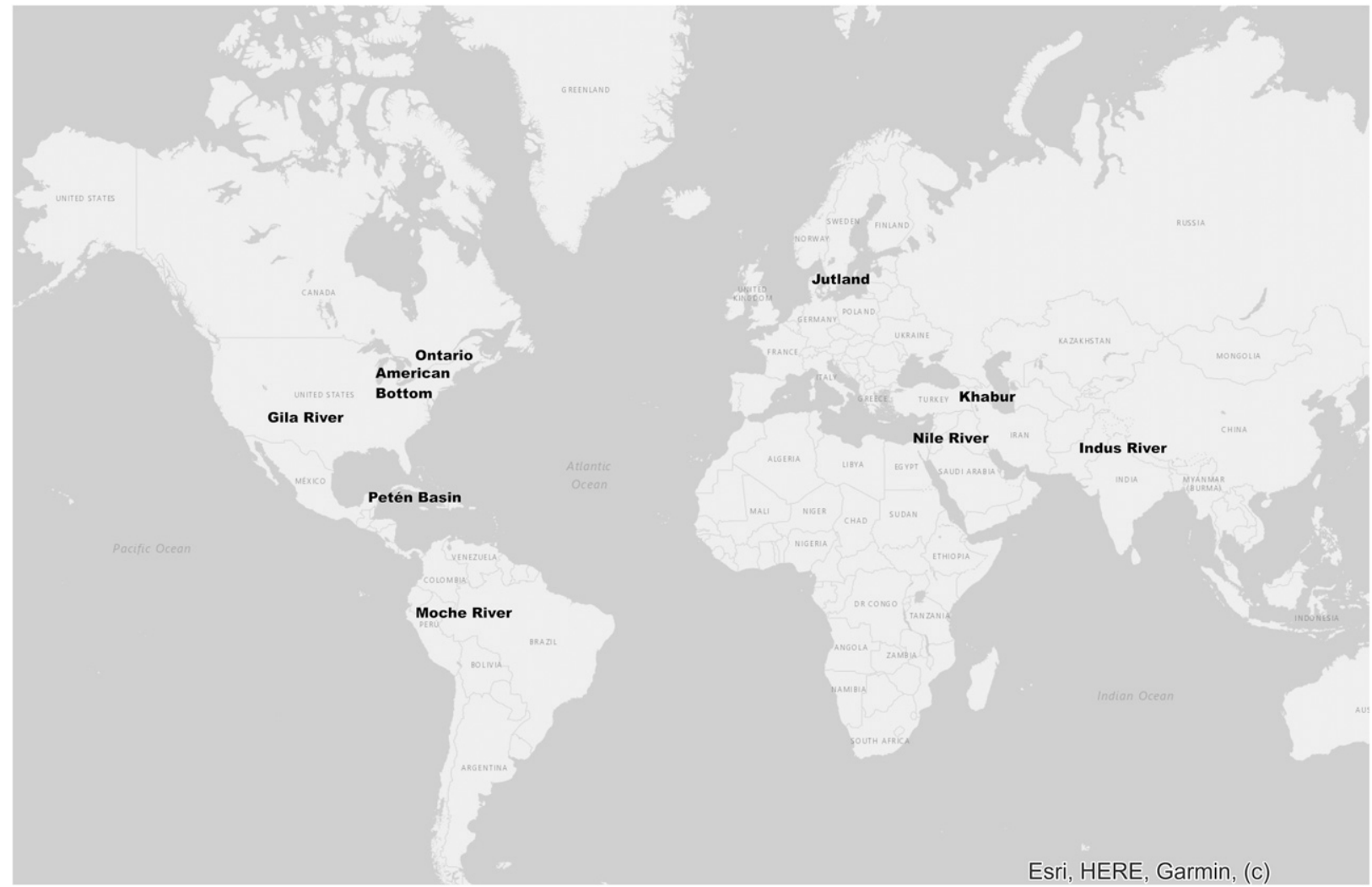

FIG. 2. Locations and names of cases used in the original Weather, Climate, and Society study (Peregrine 2018a).

The LTI is calculated as the average standardized scores on the six variables listed in Table 3 . Societies that score lower on the LTI tend to have fewer social norms and greater tolerance for violations of them, while societies that score higher on the LTI tend to have more strongly enforced norms and less tolerance for violations of them. Since this is a replication, the LTI was coded in exactly in the same manner as the previous study; however, it proved to be a somewhat less robust index with these data, having an alpha of 0.676 , which is lower than desired. The variables in the LTI also loaded onto two factors instead of one (accounting for $64 \%$ of the variation), so with these data the LTI is not as robust as in the initial study. While this does indicate more random error in these data than those used in the previous study, it does not in itself prevent the replication attempt.

The dependent variables in the analysis are the six measures of social change listed in Table 4. The six dependent variables were coded by contrasting the conditions for the roughly 20 -yr period prior to $536 \mathrm{CE}$ and those for the roughly 20 -yr period following. Data of fine enough resolution to keep within those 20 -yr ranges were not always available, and in those cases data with the best temporal resolution available for the periods both before $536 \mathrm{CE}$ and after were employed. In all cases the values coded were within a 100-yr range of 536 CE. One might note that seven dependent variables were analyzed in the previous study. I found that one of them, "change in household organization," was not reliable, and so it was dropped in this replication. In addition to the six dependent variables used in the previous study, a new index variable is also analyzed here-the social change index (SCI). The SCI is calculated as average standardized scores on the six dependent variables. The SCI has an alpha of 0.776 but loads onto two factors (together explaining $76.8 \%$ of the variance), so it, like the LTI, is not as robust as desired. However, it is a useful measure of overall change.

It is important to emphasize that there is diversity in all societies, and there is also diversity in the inferences made about past societies (van Bavel et al. 2019). Our knowledge and interpretations of the past change as more information is uncovered. This is the reality of research in the historical sciences. The data presented here are the best approximation of reality based on the available information but in no way represent the "truth" about the past. The online materials are intended to provide as much supporting information as possible so that other scholars might examine these data, 


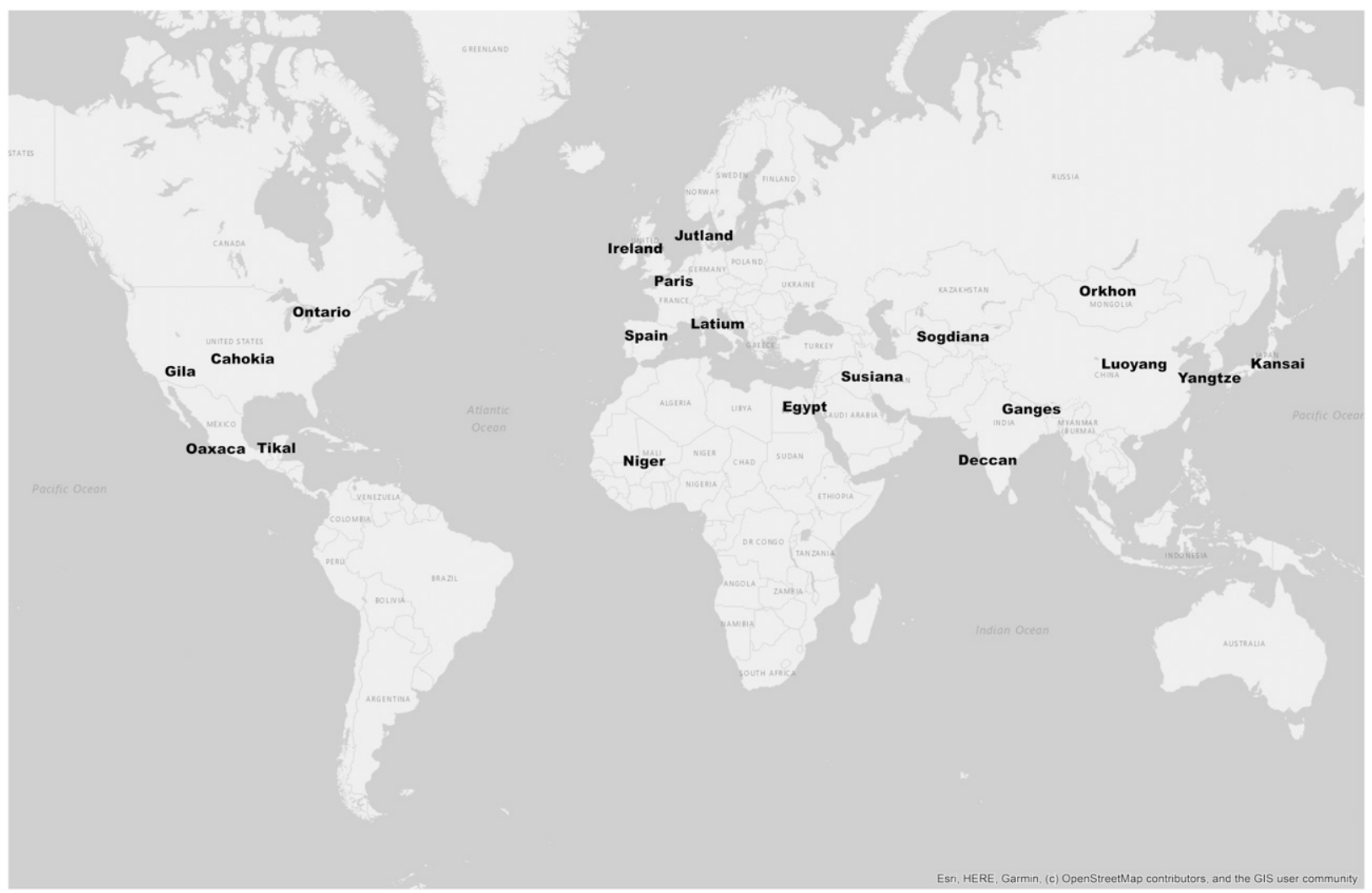

FIG. 3. Locations and names of the 20 sample cases.

make corrections or provide new interpretations, recode variables based on their own protocols, and either replicate of falsify the results presented here.

Coding of all of the variables was done on the Dacura platform, which allowed both numeric codes and all supporting documentation to be placed directly into a "resource description framework (RDF)-triplestore" data format (Peregrine et al. 2018). RDF-triplestore data provide semantic links between coded information that allow for both data harvesting and sharing on the semantic web. In the first stage of coding quotations from textual sources (primary and secondary historical documents, archaeological site reports, etc.) providing information about each variable were input along with their bibliographical information. Once all of the source materials were input, each set of quotations was read by me and a research assistant and initial coding decisions were made. These codings were revisited once all of the cases were completed. Experts listed as contributors to the Seshat Databank (http://seshatdatabank.info/seshatabout-us/contributor-database/), were invited to review the codings and underlying source materials (although not all did so, and the input from these reviewers thus varied highly among cases). Revisions were made on the basis of experts' responses and suggested additional source materials, and final codes were established. Again, these codes are only final for this project, and other scholars are encouraged to correct and improve

TABLE 4. Dependent variables used in the analyses and to create the SCI. All are scored on a none, some, or much scale.

\begin{tabular}{|c|c|}
\hline Variable & Question coded for SCI \\
\hline Change in population & Was there a change in population size or migration? \\
\hline Change in famine or disease & Was there a change in the frequency or intensity of famine or disease? \\
\hline Change in conflict & Was there a change in the frequency or intensity of conflict? \\
\hline Change in village organization & Was there a change in the organization of communities? \\
\hline Change in regional organization & Was there a change in the regional organization of the society? \\
\hline $\begin{array}{l}\text { Change in ritual architecture and } \\
\text { organization }\end{array}$ & $\begin{array}{l}\text { Was there a change in the religious or ritual organization of the } \\
\text { society? }\end{array}$ \\
\hline
\end{tabular}


them. The data used in this study are available for viewing and commentary on the Human Relations Area Files Advanced Research Center website (http:// harfarc.org).

It is important to note that, for all of the variables, coding focused, to the extent possible, on a single community or region within the larger case. This is standard practice in cross-cultural research and is done as a way to control for the range of social diversity found in different geographical locations within any given society (Ember and Ember 2000). In addition, the variables making up the CEI and LTI were coded with information describing conditions as close to $536 \mathrm{CE}$ as possible. As noted above, the expectation was that the information coded would be within 20 years of $536 \mathrm{CE}$, and this was accomplished for most of the coded values. In all cases the coded values represent conditions reported after $500 \mathrm{CE}$.

\section{Results and discussion}

This section describes the results of the replication study. Two hypotheses were tested in the original paper, and here the same hypotheses are tested using the new dataset described above, the same set of variables, and the new social change index.

Hypothesis 1 was that societies with more corporately oriented polities are more resilient to climate-related disasters than are societies in which leaders tightly control access to political authority. Table 5 presents the results of Pearson's one-tailed correlations between the CEI, the six dependent variables, and the SCI (Table 5, column 1). One-tailed correlations are employed because the hypothesized relationships are directional. As in the original study, there appears to be modest support for hypothesis 1 . All of the correlations are in the expected direction, and "change in conflict" is statistically significant $(p<0.034)$. "Change in population," "famine and disease," and "communal ritual" are marginally significant. Interestingly, the SCI is also significantly correlated with the CEI $(r=0.465$, with $p<0.020)$ and in the expected direction. This would suggest that having a more corporately oriented political structure tended to minimize conflict during the LALIA and appears to have limited social change in general.

Hypothesis 2 was that societies with tighter adherence social norms are more resilient to climate-related disasters than are societies with looser adherence to social norms. Table 5 also presents the results of Pearson's one-tailed correlations between the LTI, the six dependent variables, and the SCI (Table 5, column 3). The results of Pearson's correlations show little support for hypothesis 2 . None are in the expected direction and one, the correlation with "famine and disease," is statistically significant in the opposite direction to that hypothesized ( $r=0.415$, with $p<0.034$; the hypothesized correlation should be negative) The correlation with the SCI is also marginally significant, but in the wrong direction. Thus, it appears that adherence to social norms did not provide meaningful resilience to social change during the LALIA.

In research following my original Weather, Climate, and Society article I found that variation in political hierarchy was an important mediating variable between the LTI, the CEI, and the dependent variables (e.g., Peregrine 2018b, 2020a). With that in mind partial correlations of the LTI and the CEI with the dependent variables controlling for political hierarchy are also presented in Table 5. Political hierarchy is defined as the number of levels of jurisdictional hierarchy above the local community and varies between 0 and 5 . Not surprisingly, given that political hierarchy has already been identified as a mediating variable, the correlation coefficients and levels of significance are higher for the partial correlations. Indeed, "change in population" $(p<0.008)$, "village organization" $(p<0.024)$, "regional organization" ( $p<0.007)$, and "ritual organization" ( $p<0.004)$ are all significantly associated with the CEI when controlling for political hierarchy (Table 5, column 2) [and, interestingly, "change in conflict" no longer is associated-see Peregrine (2018b) for more discussion], whereas only "change in ritual organization" is significantly associated with the LTI, but in the wrong direction (Table 5, column 4) $(r=$ 0.495 , with $p<0.016$; the hypothesized correlation should be negative).

From the results presented in Table 5, it is clear that this replication provided somewhat weaker support for hypothesis 1 than the previous study, and somewhat stronger evidence to reject hypothesis 2 . One reason for the weaker results regarding hypothesis 1 might be that the sample size here is about one-third smaller than that used in the original study. To provide a better evaluation of this smaller sample, I conducted Bayesian correlations between the LTI, CEI, and SCI to determine if the inferences based on the Pearson's correlations are reasonable. The Bayes factors (BF) (using a rectangular prior probability distribution because the priors are unknown) are given in Table 5 (bottom row in columns 1 and 3) and present a similar picture to the results of the frequentist analysis. Perhaps not surprisingly, the BFs suggest that there is weak support for hypothesis $1(\mathrm{BF}=0.716)$ and modest support against hypothesis $2(\mathrm{BF}=1.587)$.

Although this replication produced slightly weaker results than my previous study, this study does appear to be a successful replication. The results from this and my 
TABLE 5. Pearson's $r$ correlations between independent variables (columns) and dependent variables (rows). Columns 1 and 3 show the results of one-tailed Pearson's correlations; columns 2 and 4 show the results of one-tailed partial correlations controlling for political hierarchy. One asterisk indicates significance at the 0.05 level, and two asterisks means significance at the 0.01 level.

\begin{tabular}{|c|c|c|c|c|c|}
\hline & & 1) $\mathrm{CEI}$ & $\begin{array}{l}\text { 2) CEI controlling for } \\
\text { political hierarchy }\end{array}$ & 3) LTI & $\begin{array}{l}\text { 4) LTI controlling for } \\
\text { political hierarchy }\end{array}$ \\
\hline \multirow[t]{3}{*}{ Change in population } & $r=$ & 0.342 & $0.547^{* *}$ & 0.223 & 0.306 \\
\hline & $p<$ & 0.070 & 0.008 & 0.173 & 0.101 \\
\hline & $N=$ & 20 & 17 & 20 & 17 \\
\hline \multirow[t]{3}{*}{ Change in famine or disease } & $r=$ & 0.353 & 0.099 & $0.415^{*}$ & 0.233 \\
\hline & $p<$ & 0.063 & 0.343 & 0.034 & 0.169 \\
\hline & $N=$ & 20 & 17 & 20 & 17 \\
\hline \multirow[t]{3}{*}{ Change in conflict } & $r=$ & $0.415^{*}$ & -062 & 0.297 & -0.149 \\
\hline & $p<$ & 0.034 & 0.400 & 0.102 & 0.271 \\
\hline & $N=$ & 20 & 17 & 20 & 17 \\
\hline \multirow[t]{3}{*}{ Change in village organization } & $r=$ & 0.239 & $0.460^{*}$ & 0.190 & 0.318 \\
\hline & $p<$ & 0.155 & 0.024 & 0.211 & 0.092 \\
\hline & $N=$ & 20 & 17 & 20 & 17 \\
\hline \multirow{3}{*}{$\begin{array}{l}\text { Change in regional } \\
\text { organization }\end{array}$} & $r=$ & 0.235 & $0.554^{* *}$ & 0.087 & 0.252 \\
\hline & $p<$ & 0.160 & 0.007 & 0.357 & 0.149 \\
\hline & $N=$ & 20 & 17 & 20 & 17 \\
\hline \multirow{3}{*}{$\begin{array}{l}\text { Change in ritual architecture } \\
\text { and organization }\end{array}$} & $r=$ & 0.322 & $0.584^{* *}$ & 0.326 & $0.495^{*}$ \\
\hline & $p<$ & 0.083 & 0.004 & 0.081 & 0.016 \\
\hline & $N=$ & 20 & 17 & 20 & 17 \\
\hline \multirow[t]{3}{*}{ SCI } & $r=$ & $0.463^{*}$ & $0.537^{* * *}$ & 0.374 & 0.360 \\
\hline & $p<$ & 0.020 & 0.009 & 0.052 & 0.065 \\
\hline & $N=$ & 20 & 17 & 20 & 17 \\
\hline Bayes factor & & 0.716 & & 1.587 & \\
\hline
\end{tabular}

previous study suggest that societies with more corporately oriented political structures tend to be more resilient to catastrophic climate-related disasters. These results mirror an idea found widely in the current literature on resilience to disaster-that greater political inclusiveness and broader participation in decisionmaking leads to greater social resilience (e.g., Brugger and Crimmins 2015; Cinner and Barnes 2019; Dilling et al. 2015; Lebel et al. 2006; Norris et al. 2008). On the other hand, this replication and the results of my previous study offer only weak support for the idea that tighter societies are more resilient than looser ones [also see Jackson et al. (2020) for a similar conclusion that is based on ethnographic data]. This is somewhat surprising for, as noted above, societal tightness has been empirically shown to be associated with social resilience to disasters in several studies (Gelfand et al. 2011; Harrington and Gelfand 2014). Why does societal tightness explain social resilience in these other studies while not in my previous study and this replication? I suggest the reason might be that societal tightness provides resilience only in specific socioenvironmental conditions, particularly those where sudden, localized climate-related disasters are frequent (cf. Jackson et al. 2020).

As pointed out by Davidson et al. (2016), strategies of resilience may differ between domains of impact (i.e., urban or community vs socioecological), and Lorenz and Dittmer (2016) argue that different scales of impact (i.e., societal-wide vs community) may also require different strategies of resilience. Both this and my previous paper focus specifically on catastrophic climate-related disasters rather than the more episodic ones used in research on societal tightness and resilience. Gelfand and colleagues (2011; Harrington and Gelfand 2014) focused on climate-related disasters of much smaller scales than the ones considered here. The disasters they considered are such things as floods, tornadoes, and the like, which might impact individual communities or regions within a society but do not have societal-wide impact (see Harrington and Gelfand 2014, p. 7992; also Lorenz and Dittmer 2016, p. 37). So, I suggest that what may be reflected in these conflicting results is that corporate political orientation provides greater social resilience to catastrophic climate-related disasters while societal tightness provides greater resilience to smallerscale disasters.

That corporate political orientation may provide greater social resilience to catastrophic climate-related disasters while societal tightness may provide greater resilience to smaller-scale disasters makes sense in the context of polycentric governance as a means of building resilience, a concept used widely in resilience research (e.g., Djalante et al. 2011; Fraser and Kirbyshire 2017). 
Polycentric governance is usually defined as a system in which there are multiple centers of power or decisionmaking in which authority is overlapping or shared between centers, creating redundancy and efficient information exchange that, in turn, provides resilience in the system (Chaffin et al. 2014). One of the central elements of polycentric governance is participation and collaboration in the political process, specifically because the existence of multiple, overlapping centers of authority provide citizens with greater opportunities for political participation, decision-making, and information exchange both within and outside the polity. These appear to be key elements of resilience (Carpenter et al. 2012). They are also key elements of corporate governance strategies. Resilience in polycentric systems may also rest in their tendency to create forms of social capital that are adaptive to the risks faced by polities in specific socioenvironmental contexts (Berardo and Lubell 2016).

Social capital refers to the social networks and interpersonal relationships that tie communities together (Ntontis et al. 2020; Putnam 1995; Woolcock 1998), and it is widely argued that such ties are central to resilience (e.g., Aldrich 2012; Norris et al. 2008). Putnam (2000, 18-24) suggests that there are three basic forms of social capital: bridging, bonding, and linking. Corporate strategies, particularly the emphasis on broad political participation and citizen-oriented governance, seems most closely related to bridging social capital, which refers to networks of social ties that link diverse individuals and groups together across a community. Indeed Putnam (2000, 31-47) includes political participation in the form of voting, interest in public affairs, and participation in political and civic organizations as measures of bridging social capital (also Onyx and Bullen 2000). Thus, bridging social capital seems similar to what would be expected in corporately oriented societies. Bonding social capital, in contrast, reflects interrelational ties that bind together individuals within social groups. In this way bonding social capital seems quite similar to the idea of societal tightness (cf. Ntontis et al. 2020).

Bridging social capital has been associated with resilience following catastrophic natural disasters, such as those experienced by societies during the LALIA, while bonding social capital seems more effective in societies were smaller natural disasters are frequent (Jordan 2014; Masud-All-Kamal and Hassan 2018; Ntontis et al. 2020), such as in those societies examined by Gelfand and colleagues. This appears to occur because bridging social capital, by providing a network of ties that link individuals and organizations across a community, allows communities to prepare well for major disasters and to have effective, coordinated response and recovery plans and practices in place (e.g., Berardo and Lubell 2016; Wilhelmi and Hayden 2010).

Bonding social capital, on the other hand, appears more effective in situations where there are frequent smaller disasters because neighbors and family are typically the first responders in such disaster situations (van Bavel and Curtis 2016). Where disasters are common, strong bonds among individuals in a community provide for rapid response and reconstruction (Jordan 2014). In addition, Berardo and Scholz (2010) have argued that bonding social capital develops in contexts where there is a high risk of defection. Defection might be a problem where small-scale disasters are common because, without strong bonding social capital, unaffected community members might leave or focus on their own recovery rather than to stay and assist other community members in more dire straits.

\section{Conclusions}

I suggest, on the basis of the analyses presented here and the literature discussed above, that corporate governance strategies, and particularly the fostering of political participation and extracommunity interaction, may provide a context for the development of bridging social capital in the context of catastrophic climaterelated disasters. This bridging social capital, in turn, may contribute to resilience in these contexts. Societal tightness, on the other hand, may provide resilience where disasters are more frequent and localized because of its ability to foster bonding social capital that creates a context in which community members are expected to help one another in the immediate aftermath of a disaster.

These conclusions have potentially important implications for policy development. First, they support the idea that social capital fosters resilience, but they also suggest that different forms of social capital provide resilience to different hazards. Bonding social capital, related to societal tightness, may provide resilience in contexts were communities need to develop mechanisms to minimize defection and ensure cooperation when localized disasters strike (cf. Hamilton and Lubell 2019). Bridging social capital may provide resilience where there is little risk of defection but great need for coordination and multilevel response (Berardo and Lubell 2016), as in the aftermath of catastrophic climaterelated disasters.

What this replication seems to indicate is that, just as physical infrastructure is designed to mitigate specific hazards, so social capital should be designed for specific hazards (Comfort et al. 2010). Where localized disasters are expected (e.g., tornadoes or floods) bonding social capital may provide the best resilience. Where wide 
impact disasters are expected (e.g., hurricanes or volcanic eruptions) bridging social capital may provide greater resilience. The key implication is that those developing policies to build social capital may need to consider the idea that no one form of social capital provides resilience in all contexts. Building social capital may not in itself be the answer to building resilience; rather, social capital may need to be designed to fit specific contexts. In contexts where catastrophic disasters are anticipated, implementing strategies employed in more corporately oriented polities may improve resilience, whereas resilience may be better fostered in contexts where smaller and more frequent disasters are anticipated by implementing strategies that create tight societal norms and means of enforcement. How might this be accomplished?

Elsewhere I have suggested that to build bridging social capital policy makers might encourage stakeholders at the local level to participate in decision-making about disaster response and management (Peregrine 2020a; also Aldrich and Meyer 2015; Burby 2003) by actively communicating with them and encouraging them to give input at meetings and forums (Horney et al. 2016). I noted that this resembles the U.S. Federal Emergency Management Agency's "Whole Community" approach to disaster response and management (FEMA 2011) under which local emergency managers are encouraged to focus their efforts on creating engagement strategies and programs tied directly to the specific characteristics and needs of the community. I also suggested that policy makers might encourage regular communication between local decision-makers, emergency and disaster response personnel, and disaster response organizations to ensure smooth communication at appropriate levels during a disaster response (Aldrich 2010; Aldrich and Meyer 2015; White et al. 2015).

Here I put forward an additional mechanism through which both bridging and bonding social capital might be created: collaborative forums. Collaborative forums, as the name suggests, seek to bring experts and stakeholders together to develop collaborative answers to complex problems. Such forums are structured to foster bonding social capital. Daniel Nohrstedt (2018), however, has recently demonstrated that such forums actually produce bridging capital through introductions among participants from diverse stakeholder groups made by central actors in the forum. Collaborative forums are also important mechanisms of information exchange, as stakeholders and experts are compelled not only to share information but to work through complex knowledge domains in order to solve the problems with which they are tasked. And, in working through complex knowledge domains, the participants also build personal bonds, thus creating both bridging and bonding social capital simultaneously (Nohrstedt 2018). I therefore suggest that policy makers might work to develop a range of collaborative forums on aspects of climate-related disasters of local concern (e.g., flooding, heatwaves) (cf. Moss et al. 2019, p. 469). Such forums may serve not only to develop plans for disaster response and management, but also help to construct the social capital necessary for greater resilience to climate-related disasters.

Acknowledgments. I must thank Raphael Neukom, Joel Gunn, Felix Riede, and Payson Sheets for their many stimulating discussions, suggestions, and insights about the Late Antique Little Ice Age and its impact; Michele Gelfand for assisting with development of the tightness-looseness index; and my hardworking research assistant Joe Kortenhof. I also thank Carol Ember, Marilyn Hentz, and the entire staff at HRAF for their ongoing support. In addition, I thank the staff at DataChemist, and especially Kevin Feeney, for their development of the Dacura interface and their ongoing assistance with data input and curation. This project was supported by the National Science Foundation (Award SMA-1416651) and the Army Research Office (Contract W911NF-17-1-0441). The views and conclusions contained in this document are those of the author and should not be interpreted as representing the official policies, either expressed or implied, of the Army Research Office or the U.S. government. The U.S. government is authorized to reproduce and distribute reprints for government purposes notwithstanding any copyright notation herein. Both awards were administered through the HRAF Advanced Research Center (hrafARC) at Yale University.

\section{REFERENCES}

Aldrich, D., 2010: Power of the people: Social capital's role in recovery from the 1995 Kobe earthquake. Nat. Hazards, 56, 595611, https://doi.org/10.1007/s11069-010-9577-7.

_- 2012: Building Resilience: Social Capital in Post-Disaster Recovery. University of Chicago Press, $248 \mathrm{pp}$.

ience. Amer. Behav. Sci., 59, 254-269, https://doi.org/ 10.1177/0002764214550299.

Arjava, A., 2005: The mystery cloud of 536 C.E. in the Mediterranean sources. Dumbarton Oaks Pap., 59, 73-94, https://doi.org/10.2307/ 4128751.

Berardo, R., and J. Scholz, 2010: Self-organizing policy networks: Risk, partner selection, and cooperation in estuaries. Amer. J. Polit. Sci., 54, 632-649, https://doi.org/10.1111/j.15405907.2010.00451.x.

, and M. Lubell, 2016: Understanding what shapes a polycentric governance system. Pub. Adm. Rev., 76, 738-751, https://doi.org/10.1111/puar.12532. 
Brugger, J., and M. Crimmins, 2015: Designing institutions to support local-level climate change adaptation: Insights from a case study of the U.S. Cooperative Extension System. Wea. Climate Soc., 7, 18-38, https://doi.org/10.1175/WCAS-D-1300036.1.

Büntgen, U., and Coauthors, 2016: Cooling and societal change during the late Antique Little Ice Age from 536 to around 660 AD. Nat. Geosci., 9, 231-236, https://doi.org/10.1038/ ngeo2652.

Burby, R., 2003: Making plans that matter: Citizen involvement and government action. J. Amer. Plann. Assoc., 69, 33-49, https://doi.org/10.1080/01944360308976292.

Carpenter, S., and Coauthors, 2012: General resilience to cope with extreme events. Sustainability, 4, 3248-3259, https://doi.org/ $10.3390 / \mathrm{su} 4123248$.

Chaffin, B., H. Gosnell, and B. Cosens, 2014: A decade of adaptive governance scholarship: Synthesis and future directions. Ecol. Soc., 19, 56, https://doi.org/10.5751/ES-06824-190356.

Cinner, J., and M. Barnes, 2019: Social dimensions of resilience in socio-ecological systems. One Earth, 1, 51-56, https://doi.org/ 10.1016/j.oneear.2019.08.003.

Comfort, L., A. Boin, and C. Demchack, 2010: Designing Resilience: Preparing for Extreme Events. University of Pittsburgh Press, 360 pp.

Davidson, J. L., and Coauthors, 2016: Interrogating resilience: Toward a typology to improve its operationalization. Ecol. Soc., 21, 27, https://doi.org/10.5751/ES-08450-210227.

Dilling, L., K. Lackstrom, B. Haywood, K. Dow, M. Lemos, J. Berggren, and S. Kalafatis, 2015: What stakeholder needs tell us about enabling adaptive capacity: The intersection of context and information provision across regions of the United States. Wea. Climate Soc., 7, 5-17, https://doi.org/ 10.1175/WCAS-D-14-00001.1.

Djalante, R., C. Holley, and F. Thomalla, 2011: Adaptive governance and managing resilience to natural hazards. Int. J. Disaster Risk Sci., 2 (4), 1-14, https://doi.org/10.1007/s13753-011-0015-6.

Dow, M. M., 2007: Galton's Problem as multiple network autocorrelation effects: Cultural trait transmission and ecological constraint. Cross-Cultural Res., 41, 336-363, https://doi.org/ 10.1177/1069397107305452.

Dull, R., and Coauthors, 2019: Radiocarbon and geologic evidence reveal Ilopango volcano as source of the colossal 'mystery' eruption of 539/40 CE. Quat. Sci. Rev., 222, 105855, https:// doi.org/10.1016/j.quascirev.2019.07.037.

Ember, C. R., and M. Ember, 2000: Cross-Cultural Research Methods. AltaMira, 164 pp.

FEMA, 2011: A whole community approach to emergency management: Principles, themes, and pathways for action. FEMA Doc. 104-008-1, 28 pp., https://www.fema.gov/media-library-data/ 20130726-1813-25045-0649/whole_community_dec2011_2_.pdf .

Fraser, A., and A. Kirbyshire, 2017: Supporting governance for climate resilience: Working with political institutions. ODI Working Paper 517, 31 pp., https://www.odi.org/ sites/odi.org.uk/files/resource-documents/11699.pdf.

Gelfand, M., and Coauthors, 2011: Differences between tight and loose cultures: A 33-nation study. Science, 332, 1100-1104, https://doi.org/10.1126/science.1197754.

Gräslund, B., and N. Price, 2012: Twilight of the Gods? The "dust veil event" of A.D. 536 in critical perspective. Antiquity, 86, 428-443, https://doi.org/10.1017/S0003598X00062852.

Gunn, J. D., 2000: The Years without Summer: Tracing AD 536 and Its Aftermath. BAR International Series, Vol. 872, Archaeopress, $170 \mathrm{pp}$.
Hamilton, M., and M. Lubell, 2019: Climate change adaptation, social capital, and the performance of polycentric governance institutions. Climatic Change, 152, 307-326, https://doi.org/ 10.1007/s10584-019-02380-2.

Harrington, J., and M. Gelfand, 2014: Tightness-looseness across the 50 United States. Proc. Natl. Acad. Sci. USA, 111, 7990 7995, https://doi.org/10.1073/pnas.1317937111.

Holling, C. S., L. Gunderson, and G. Peterson, 2002: Sustainability and panarchy. Panarchy: Understanding Transformations in Human and Natural Systems, L. Gunderson and C. S. Holling, Eds., Island Press, 63-102.

Horney, J., D. Spurlock, S. Grabich, and P. Berke, 2016: Capacity for stakeholder participation in recovery planning. Plann. Pract. Res., 31, 65-79, https://doi.org/10.1080/02697459.2015.1104220.

Jackson, J., M. Gelfand, and C. Ember, 2020: A global analysis of cultural tightness and its relationship with ecological threat, social complexity, and social structure. Proc. Roy. Soc., in press.

Jordan, J., 2014: Swimming alone? The role of social capital in enhancing local resilience to climate stress: A case study from Bangladesh. Climate Dev., 7, 110-123, https://doi.org/10.1080/ 17565529.2014.934771.

Kahn, M., 2005: The death toll from natural disasters: The role of income, geography, and institutions. Rev. Econ. Stat., 87, 271284, https://doi.org/10.1162/0034653053970339.

Lebel, L., J. Anderies, B. Campbell, C. Folke, S. Harfield-Dodds, T. Hughes, and J. Wilson, 2006: Governance and the capacity to manage resilience in regional social-ecological systems Ecol. Soc., 11, 19, https://doi.org/10.5751/ES-01606-110119.

Lorenz, D., and C. Dittmer, 2016: Resilience in catastrophes, disasters, and emergencies. New Perspectives on Resilience in Socio-Economic Spheres, A. Maurer, Ed., Springer VS, 25-59.

Löwenborg, D., 2012: An Iron Age shock doctrine: Did the A.D 536-7 event trigger large-scale social changes in the Malaren Valley area? J. Archaeol. Ancient Hist., 4, 1-29.

Masud-All-Kamal, M., and S. M. Hassan, 2018: The link between social capital and disaster recovery: Evidence from coastal communities in Bangladesh. Nat. Hazards, 93, 1547-1564, https://doi.org/10.1007/s11069-018-3367-z.

Moss, R. H., and Coauthors, 2019: Evaluating knowledge to support climate action: A framework for sustained assessment. Wea. Climate Soc., 11, 465-487, https://doi.org/10.1175/WCASD-18-0134.1.

Murdock, G. P., and S. F. Wilson, 1972: Settlement patterns and community organization: Cross-cultural codes 3. Ethnology, 11, 254-295, https://doi.org/10.2307/3773219.

Neukom, R., N. Steiger, J. J. Gómez-Navarro, J. Wang, and J. P. Werner, 2019: No evidence for globally coherent warm and cold periods over the preindustrial Common Era. Nature, 571, 550-554, https://doi.org/10.1038/s41586-019-1401-2.

Nohrstedt, D., 2018: Bonding and bridging relationships in collaborative forums responding to weather warnings. Wea. Climate Soc., 10, 521-536, https://doi.org/10.1175/WCAS-D17-0134.1.

Nooren, K., and Coauthors, 2017: Explosive eruption of El Chichćon volcano (Mexico) disrupted 6th century Maya civilization and contributed to global cooling. Geology, 45, 175178, https://doi.org/10.1130/G38739.1.

Norris, F., S. Stevens, B. Pfefferbaum, K. Wyche, and R. Pfefferbaum, 2008: Community resilience as a metaphor, theory, set of capacities, and strategy for disaster readiness. Amer. J. Community Psychol., 41, 127-150, https://doi.org/10.1007/ s10464-007-9156-6. 
Ntontis, E., J. Drury, E. Amlôt, G. Rubin, and R. Williams, 2020: What lies beyond social capital? The role of social psychology in building community resilience to climate change. Traumatology, https://doi.org/10.1037/trm0000221, in press.

Onyx, J., and P. Bullen, 2000: Measuring social capital in five communities. J. Appl. Behav. Sci., 36, 23-42, https://doi.org/ 10.1177/0021886300361002.

Paton, D., 2006: Disaster resilience: Building capacity to co-exist with natural hazards and their consequences. Disaster Resilience: An Integrated Approach, D. Paton and D. Johnston, Eds., Charles Thomas, 3-10.

Peregrine, P. N., 2018a: Social resilience to climate-related disasters in ancient societies: A test of two hypotheses. Wea. Climate Soc., 10, 145-161, https://doi.org/10.1175/WCAS-D17-0052.1.

_ 2018b: Reducing post-disaster conflict: A cross-cultural test of four hypotheses using archaeological data. Environ. Hazards, 18, 93-110, https://doi.org/10.1080/17477891.2018.1476317. , 2020a: Political participation and social resilience to the A.D. 536/540 atmospheric catastrophe. Catastrophes in Context, F. Riede and P. Sheets, Eds., Berghahn Books, in press.

_ 2020b: Climate and social change at the start of the Late Antique Little Ice Age. Holocene, in press.

—, R. Brennan, T. Currie, K. Feeney, P. François, P. Turchin, and H. Whitehouse, 2018: Dacura: A new solution to data harvesting and knowledge extraction for the historical sciences. Hist. Methods, 51, 165-174, https://doi.org/10.1080/ 01615440.2018.1443863.

Putnam, R., 1995: Bowling alone: America's declining social capital. J. Democracy, 6, 65-78, https://doi.org/10.1353/jod.1995.0002.

- 2000: Bowling Alone: The Collapse and Revival of American Community. Simon and Schuster, 544 pp.

Riede, F., 2014: Towards a science of past disasters. Nat. Hazards, 71, 335-362, https://doi.org/10.1007/s11069-013-0913-6.

—_, 2017: Past-forwarding ancient calamities. Pathways for making archaeology relevant in disaster risk reduction research. Humanities, 6, 79, https://doi.org/10.3390/h6040079.

Tiernan, A., L. Drennan, J. Nalau, E. Onyango, L. Morrissey, and B. Mackey, 2019: A review of themes in disaster resilience literature and international practice since 2012. Policy Des. Pract., 2, 53-74, https://doi.org/10.1080/25741292.2018.1507240.

Toohey, M., K. Krüger, M. Sigl, F. Stordal, and H. Svensen, 2016: Climatic and societal impacts of a volcanic double event at the dawn of the Middle Ages. Climatic Change, 136, 401-412, https://doi.org/10.1007/s10584-016-1648-7.

Turchin, P., and Coauthors, 2018: Quantitative historical analysis uncovers a single dimension of complexity that structures global variation in human social organization. Proc. Natl. Acad. Sci. USA, 115, E144-E151, https://doi.org/10.1073/ pnas. 1708800115 .

van Bavel, B. J. P., and D. Curtis, 2016: Better understanding disasters by better using history: Systematically using the historical record as one way to advance research into disasters. Int. J. Mass Emerg. Disasters, 34, 143-169.

—_ - M. Hannaford, M. Moastsos, J. Roosen, and T. Soens, 2019: Climate and society in long-term perspective: Opportunities and pitfalls in the use of historical datasets. Wiley Interdiscip. Rev.: Climate Change, 10, e611, https://doi.org/10.1002/WCC.611.

Walker, B., C. S. Holling, S. Carpenter, and A. Kinzig, 2004: Resilience, adaptability and transformability in socialecological systems. Ecol. Soc., 9, 5, https://doi.org/10.5751/ ES-00650-090205.

White, R., W. Edwards, A. Farrar, and M. J. Plodinec, 2015: A practical approach to building resilience in America's communities. Amer. Behav. Sci., 59, 200-219, https://doi.org/ 10.1177/0002764214550296.

Wilhelmi, O. V., and M. H. Hayden, 2010: Connecting people and place: A new framework for reducing urban vulnerability to extreme heat. Environ. Res. Lett., 5, 014021, https://doi.org/ 10.1088/1748-9326/5/1/014021.

Wisner, B., and I. Kelman, 2015: Community resilience to disasters. International Encyclopedia of the Social Sciences, J. D. Wright, Ed., Elsevier, 354-360.

Woolcock, M., 1998: Social capital and economic development: Toward a theoretical synthesis and policy framework. Theory Soc., 27, 151-208, https://doi.org/10.1023/A: 1006884930135. 